\title{
Comunicação/Communication
}

\section{Surto de hepatite A em área urbana de Luziânia, Estado de Goiás, 2009}

\author{
Hepatite A outbreak in an urban area of Luziânia, State of Goiás, Brazil, 2009
}

\author{
Márcia de Cantuária Tauil ${ }^{1}$, Patrícia Marques Ferreira ${ }^{1}$, Maria Cristina Ferreira de Abreu $^{2}$, Helena Cristina \\ Alves Vieira Lima ${ }^{1}$ e Aglaêr Alves da Nóbrega ${ }^{1}$
}

\begin{abstract}
RESUMO
Introdução: Os objetivos desse estudo foram confirmar a existência de um surto de hepatite A, descrever o evento por pessoa, tempo e lugar, formular hipóteses sobre modo de transmissão e propor medidas de prevenção e controle. Métodos: Realizado um estudo descritivo do tipo série de casos e investigação ambiental. Resultados: Ocorreu um surto a partir de março de 2009. Quarenta e uma (71\%) pessoas recebiam água sem tratamento no seu domicílio. Foram detectados coliformes termotolerantes em 20/58 (34\%) amostras de água. Conclusões: A investigação sugere que a hipótese principal para esse surto foi à ingestão de água contaminada.
\end{abstract}

Palavras-chaves: Hepatite A. Surto. Água.

\section{ABSTRACT}

Introduction: This paper describes the investigation to confirm an outbreak of hepatitis $\mathrm{A}$, presents the case distribution by person, time and place, formulates a hypothesis concerning the mode of transmission and presents the recommended measures for prevention and control. Methods: A descriptive study of a case series and an environmental research were conducted. Results: An outbreak of hepatitis A was confirmed beginning in March 2009. Forty one (71\%) individuals in the town received untreated water in their households. Thermotolerant coliform bacteria were detected in 20/58 (34\%) water samples. Conclusions: Consumption of contaminated water was the main hypothesis of virus transmission.

Key-words: Hepatitis A. Outbreak. Water.

Em julho de 2009, a vigilância epidemiológica do Município de Luziânia, Goiás, situado na região do entorno do Distrito Federal, detectou um aumento do número de casos de hepatite A. Os objetivos deste trabalho foram confirmar a existência de um surto de hepatite A no Município de Luziânia, descrever o evento por pessoa, tempo e lugar, formular hipóteses sobre modo de transmissão e fatores associados à infecção e propor medidas de prevenção e controle.

A investigação foi conduzida no período de 7 a 27 de julho de 2009. Trata-se de um estudo descritivo do tipo série de casos e investigação ambiental. Foi elaborado um diagrama de controle com base nos casos confirmados de hepatite A notificados no Sistema de Informação de Agravos de Notificação (SINAN) em Luziânia, de janeiro de 2000 a julho de 2009. O limite superior do canal endêmico foi calculado por meio da média mensal mais dois desvios-padrão. $\mathrm{O}$ ano de 2005 foi excluído, pois foi um ano epidêmico ${ }^{1}$.

1. Programa de Treinamento em Epidemiologia Aplicada aos Serviços do SUS, Centro de Informações Estratégicas e Resposta em Vigilância em Saúde, Departamento de Vigilância Epidemiológica, Secretaria de Vigilância em Saúde, Ministério da Saúde, Brasilia, DF. 2. Núcleo de Vigilância Epidemiológica, Secretaria Municipal de Saúde, Luziânia, GO.

Endereço para correspondência: Marcia de Cantuaria Tauil. Esplanada dos Ministérios, Ministério da Saúde, Bloco G, sobreloja, sala 137, 70058-900 Brasilia, DF.

Tel: 5561 9672-1950

e-mail: marcia.tauil@aids.gov.br; mctauil@yahoo.com.br

Recebido para publicação em 01/03/2010

Aceito em 04/06/2010
A definição de caso confirmado utilizado foi: indivíduo notificado no Sinan de 22 de março a 11 de julho de 2009, que apresentou sorologia anti-HAV IgM reagente ou vínculo epidemiológico com um caso confirmado de hepatite A por critério laboratorial. A sorologia foi realizada pela técnica padrão de ELISA no Laboratório de Saúde Pública Dr. Giovanny Cysneiros (Lacen/GO). Para coleta de dados foram realizadas entrevistas com auxílio de questionário semiestruturado. A entrevista foi realizada com o responsável quando o indivíduo era menor de 18 anos. Os dados foram analisados utilizando os Softwares Microsoft Office ${ }^{\circledast}$ 2007, Epi-Info Windows 3.5.1, Tabwin 3.2. Foram calculadas medidas de frequência, mediana e valores mínimo e máximo.

Com relação à investigação ambiental foram coletadas, por técnicos da vigilância ambiental do município, amostras de água para análise físico-química ( $\mathrm{pH}$, cloro residual livre e turbidez) e microbiológica (presença/ausência de coliformes totais e termotolerantes). Os pontos de coleta de água foram definidos em conjunto com a referida equipe de vigilância e foi realizada em casas, bairros e escolas com casos confirmados e em alguns pontos de distribuição da empresa de abastecimento de água. As amostras foram encaminhadas ao Lacen/ GO, para análise de pH e microbiológica, sendo as demais análises físico-químicas realizadas pela vigilância ambiental do município. Os resultados foram avaliados de acordo com a Portaria Ministerial MS no 518 , de 25 de março de $2004^{2}$, que dispõe sobre a qualidade da água para consumo humano e padrões de potabilidade.

No período de 4 de janeiro a 11 de julho, foram confirmados 65 casos de hepatite A. De acordo com o diagrama de controle, foram identificados surtos nas semanas epidemiológicas (SE) 12, 16 e de 20 a 25 de 2009 (Figura 1). Do dia 22 de março ao dia 11 de julho de 2009 (SE 12 a 27), foram notificados 92 casos de hepatite A,

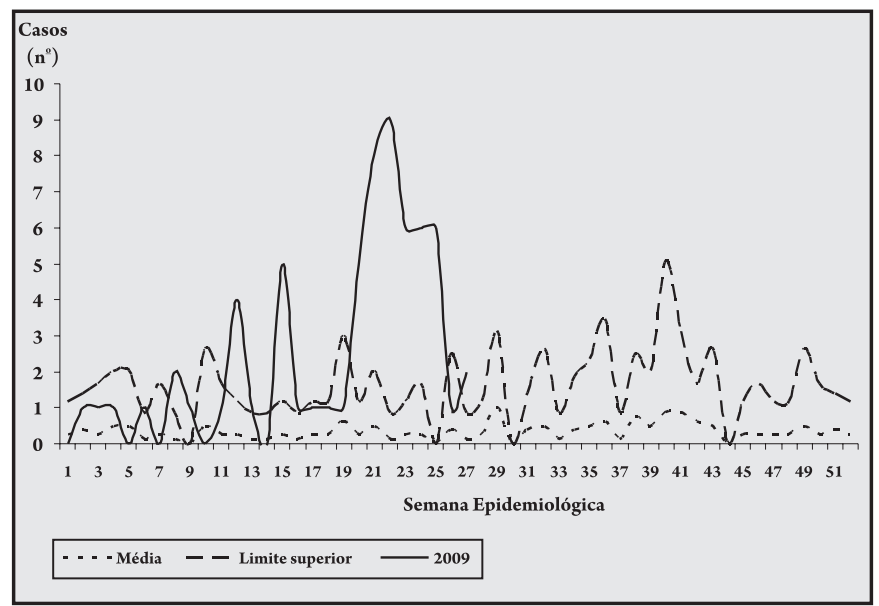

FIGURA 1 - Diagrama de controle dos casos confirmados de hepatite A, por semana epidemiológica de notificação, no período de 2000 a 2008 e casos em 2009 até a semana epidemiológica 27, Luziânia, GO, 2009. 
sendo 59 (64\%) confirmados, 29 (32\%) descartados e quatro (4\%) inconclusivos, pois houve recusa para coleta de amostra. Entre os casos confirmados, 56 (95\%) foram por critério laboratorial e três $(5 \%)$ por critério clínico-epidemiológico. Foram entrevistados 57 casos confirmados. A mediana de idade desses casos foi de sete (2-24) anos. As características demográficas dos casos confirmados são apresentadas na Tabela 1.

Com relação à oportunidade de notificação a mediana, foi de seis dias (0-126). A mediana de duração dos sintomas foi de 14 dias (2-30). Nove (16\%) pacientes foram internados, com mediana de dias de internação igual a dois (1-7). Os sinais e sintomas são apresentados na Tabela 2. Não houve óbito no período. Dezesseis (28\%) pessoas referiram contato prévio com caso de hepatite A. Os entrevistados estavam distribuídos por 19 bairros, sendo que $12(21 \%)$ casos eram de um mesmo bairro, onde as principais fontes de abastecimento de água eram Soluções de Abastecimento Individual (SAI) sem tratamento.

Trinta e quatro $(60 \%)$ pessoas relataram que recebem água de poço, 19 (33\%) da empresa de água, três (5\%) de poço e da empresa de água e um (2\%) referiu receber água de tanque da prefeitura. Entre as 23 pessoas que referiram receber água da empresa ou de tanque, sete (30\%) recebiam água tratada proveniente da estação de

TABELA 1 - Distribuição das características demográficas dos 57 casos confirmados de hepatite A, Luziânia, GO, 2009.

\begin{tabular}{lcc}
\hline Características & Número & Percentagem \\
\hline Sexo feminino & 32 & 56,0 \\
Faixa etária (anos) & 20 & 35,0 \\
$\quad 0-5$ & 21 & 37,0 \\
$\quad 6-10$ & 11 & 19,0 \\
$11-15$ & 3 & 5,0 \\
$16-20$ & 2 & 4,0 \\
$21-25$ & 0 & 0,0 \\
$\quad \geq 25$ & 57 & 100,0 \\
Residentes na área urbana de Luziânia & 43 & 75,0 \\
Escolares* & Mediana & Intervalo \\
\hline & 8 & $(0-18)$ \\
Anos de estudo do chefe da família & 5 & $(2-12)$ \\
Moradores/domicílio & 2 & $(1-4)$ \\
Moradores/cômodo & 144,00 & $(11,00-1.000,00)$ \\
\hline Renda familiar per capta/mês** $(\mathrm{R} \$)$ & &
\end{tabular}

TABELA 2 - Distribuição dos sinais e sintomas dos 57 casos confirmados de hepatite A, Luziânia, GO, 2009.

\begin{tabular}{lcc}
\hline Sinais e sintomas & Número & Percentagem \\
\hline Icterícia & 56 & 98,0 \\
Colúria & 51 & 89,0 \\
Prostação & 51 & 89,0 \\
Inapetência & 51 & 89,0 \\
Dor abdominal & 49 & 86,0 \\
Náusea & 49 & 86,0 \\
Vômito & 46 & 84,0 \\
Cefaléia & 39 & 68,0 \\
Febre & 35 & 61,0 \\
Hipocolia & 32 & 56,0 \\
Diarréia & 23 & 40,0 \\
Outros & 3 & 5,0 \\
\hline
\end{tabular}

tratamento de água (ETA), nove (40\%) recebiam água clorada de Solução de Abastecimento Coletiva (SAC) e sete (30\%) recebiam água de SAC sem tratamento. Nos 34 domicílios abastecidos por SAI, a água não era submetida às medidas de desinfecção.

Cinquenta e uma pessoas (90\%) referiram beber água da torneira antes de adoecer, cinco (9\%) água mineral e uma (2\%) água de fonte ( $b i c a)$. Entre as pessoas que consumiam água de torneira, 37 (73\%) referiram tratá-la, sendo que 36 (97\%) filtravam e uma (3\%) fervia.

Com relação ao sistema de esgoto, 40 (70\%) possuíam fossa negra, 11 (19\%) fossa séptica, quatro (7\%) rede pública de esgoto, um ( $2 \%$ ) não possuía (a céu aberto) e um (2\%) não soube informar. A distância entre o poço e a fossa mais próxima foi aferida em 28 domicílios, sendo a mediana de $15 \mathrm{~m}$ (7-30).

No período de 15 a 22 de julho de 2009, foram realizadas 58 coletas de amostra de água para análise em locais com casos confirmados: 37 em domicílios, 16 em escolas, dois em SAC sem tratamento, um na ETA e duas em fontes utilizadas pela comunidade. Das 58 amostras, foram coletadas 19 (33\%) de água tratada ou clorada, sendo realizadas análises de cloro residual livre e turbidez de 11 (58\%). Dentre essas, a concentração de cloro residual livre foi insatisfatória em quatro (36\%) amostras. O padrão de turbidez foi satisfatório em todas as amostras. $\mathrm{O} \mathrm{pH}$ foi verificado em 24 (41\%) das 58 amostras e em uma amostra de escola o $\mathrm{pH}$ foi de 5,3. Na pesquisa microbiológica foram detectados coliformes termotolerantes, presença de Escherichia coli, em 16 (43\%) amostras de casas (nove no mesmo bairro), em três (19\%) de escolas e em uma (50\%) das fontes utilizadas pela comunidade.

A baixa condição socioeconômica, a falta de saneamento básico e de condições higiênico-sanitárias adequadas da população estudada podem ter contribuído para as altas taxas de infecção. Neste estudo, houve a predominância de casos na faixa etária acima de cinco anos de idade, o que corrobora com Vitral et $\mathrm{al}^{3}$, em um estudo no Rio de Janeiro, que relata uma diminuição de casos na faixa etária menor de cinco anos.

A investigação indica que a hipótese principal para esse surto foi à ingestão de água contaminada. A presença de coliformes termotolerantes na água indica uma contaminação por fezes, o que pode favorecer a transmissão da hepatite A nessas áreas. De acordo com a literatura, o vírus pode ser encontrado até mesmo quando a água é considerada segura pelos testes bacteriológicos tradicionais, uma vez que apresenta grande resistência ao tratamento com cloro, em comparação ao grupo de bactérias coliformes que são usadas para indicar a qualidade da água ${ }^{4}$.

Para o controle imediato do surto, foram dadas orientações quanto à higiene pessoal e ao uso de hipoclorito de sódio a 2,5\% na água, conforme literatura ${ }^{5,6}$. Diferentemente de do que foi descrito por Villar et $\mathrm{al}^{7}$, sobre um surto em uma escola do Rio de Janeiro, nessa investigação não foi indicado o uso de vacina ou de imunoglobulina, pois os casos não estavam concentrados em determinado local do município e também não foi realizado inquérito sorológico para se detectar eventuais susceptíveis.

\section{CONFLITO DE INTERESSE}

Os autores declaram não haver nenhum tipo de conflito de interesse no desenvolvimento do estudo. 


\section{REFERÊNCIAS}

1. Medronho RA, Werneck GL, Perez MA. Distribuição das doenças no espaço e no tempo. In: Medronho RA, Werneck GL, Perez MA editores. Epidemiologia. $2^{a}$ ed. São Paulo: Atheneu; 2009. p. 83-102.

2. Ministério da Saúde, Brasil. Portaria do Ministério da Saúde no 518 de 25 de março de 2004.

3. Vitral CL, Gaspar AMC, Souto FJD. Epidemiological pattern and mortality rates for hepatitis A in Brazil, 1980-2002 - A Review. Mem Inst Oswaldo Cruz 2006; 101:119-127.

4. Silvia PC, Vitral CL, Barcellos C, Kawa H, Gracie R, Rosa MLG. Hepatite A no Município do Rio de Janeiro, Brasil: padrão epidemiológico e associação das variáveis sócio-ambientais - vinculando dados do Sinan aos do censo demográfico. Cad Saude Pública 2007; 23:1553-1564.

5. Ministério da Saúde, Brasil. Manual de Saneamento. Fundação Nacional de Saúde. $3^{\text {a }}$ ed. Brasília: Ministério da Saúde; 2007.

6. Sowmyanarayanan TV, Mukhopadhya A, Gladstone BP, Sarkar R, Kang G. Investigation of a hepatitis A outbreak in children in an urban slum in Vellore, Tamil Nadu, using geographic information systems. Indian J Med Res 2008; 128:32-37.

7. Villar LM, Costa MCE, Paula VS, Gaspar AMC. Hepatitis A Outbreak in a Public School in Rio de Janeiro, Brazil. Mem Inst Oswaldo Cruz 2002; 97:301-305. 